AUTORES

Alessandra

Marchioni*

alemarchioni@

hotmail.com

Daniel Allan Miranda Borba**

danielborbapgm@ gmail.com

\section{Lucas Isaac}

Soares

Mesquita ${ }^{\star \star *}$

lucasismesquita@

* Professora Doutora Mestra em Direito pela Universidade Federal de Santa Catarina (UFSC, Brasil).

\section{** Professor mestre} em Direito pela Universidade Federal de Alagoas (UFAL Brasil). Procurador do Município de Maceió (Brasil).

*** Mestrando em Direito pela UFAL.

\section{Entre os (des)caminhos dos poderes Judiciário e Legislativo brasileiro: uma análise da ampliação da terceirização na Administração Pública no contexto do RE n $760.931 /$ DF e da Lei n 13.429/2017}

El (des)encuentro entre los poderes Judicial y Legislativo brasileño: un análisis de la ampliación de la externalización en la Administración Pública en el contexto del RE $n^{0} 760.931 /$ DF y de la Ley ${ }^{0} 13.429 / 2017$

The (dis)agreements between the Brazilian judiciary and legislative branches: An analysis of the expansion of outsourcing in the Public Administration in the context of the Appeal to the Supreme Court No. 760.931/DF and of Act 13.429/2017

\section{RESUMO}

Esse artigo tem como objetivo apontar alguns dos principais elementos da teoria e da prática da "terceirização" das condições laborais do trabalhador, compreendida sob a forma de contratos de gestão ou termos de parcerias para a execução de atividades-meio, depois atividadesfim, entre a Administração Pública e a pessoa jurídica de direito privado, desde um contexto histórico normativo de resultados, tanto do ponto de vista da extensão, quanto da ampliação de seus conteúdos. Propõe-se a realizar uma abordagem sobre o Estado e o direito, sua função e seu funcionamento, a partir da perspectiva crítica ao neoliberalismo e à reestruturação produtiva em escala global, especialmente identificada na decisão do RE 760.931/DF e na Lei $\mathrm{n}^{\circ} 13.429 / 2017$. Nessa pesquisa será utilizado o método de abordagem hipotético dedutivo, em que se busca testar a hipótese da "satisfação da eficiência e modernidade" mediante os contratos de terceirização, a partir da demonstração das consequências jurídico-normativas e sociais.

\section{RESUMEN}

Este artículo pretende señalar algunos de los elementos clave de la teoría y la práctica de la "tercerización" de las condiciones laborales del trabajador, entendida en la forma de contratos de gestión o en términos de colaboración para la implementación de actividades-medios, después de actividades-fin, entre la administración pública y la persona jurídica de derecho privado, desde el marco histórico legal de los resultados, tanto desde el punto de vista de la extensión, como de la ampliación de sus contenidos. Se propone realizar una aproximación al Estado y al derecho, su función y funcionamiento, desde una perspectiva crítica al neoliberalismo y a la reestructuración productiva a escala mundial, especialmente identificada en la decisión del RE 760.931/DF y en la Ley N ${ }^{\circ}$. 13.429/2017. El método utilizado es el enfoque hipotético-deductivo, que busca probar la hipótesis de la "satisfacción de la eficiencia y modernidad" mediante la externalización de los contratos, a partir de la demonstración de las consecuencias jurídiconormativas y sociales.

\section{ABSTRACT}

This article aims to point out some of the main elements of the theory and practice involved in "outsourcing" the working conditions of the worker, understood in the form of management contracts or partnership agreements between the public administration and legal companies governed by private law for the performance of activities. This is approached from a normative historical context of results, both from the point of view of the extension, as well as the expansion of its contents. It proposes to carry out an approach to the State and the Law, its function and its functioning, from a perspective critical of neoliberalism and productive restructuring on a global scale, especially as identified in the decision of RE 760.931 / DF and Act 13.429 / 2017. In this research, the hypothetical deductive approach will be used, in which the hypothesis of "the fulfilment of efficiency and modernity" will be tested through outsourcing contracts, based on the demonstration of legal, normative and social consequences. 


\section{Introdução}

Estudos do Departamento Intersindical de Estatísticas e Estudos Socioeconômicos (DIEESE) de 2014 apontam para os inúmeros impactos sociais e econômicos dos chamados contratos "terceirizados" sobre a qualidade de vida do trabalhador e sua família. Entre os resultados estão: a maior taxa da rotatividade dos trabalhadores, o número superior de quantidade de horas trabalhadas e os salários inferiores. Não obstante a isso, observa-se que o número de trabalhadores terceirizados no serviço público federal já alcança 35\% de todas as contratações.

Esse artigo tem como objetivo apontar alguns dos principais elementos da teoria e da prática da "terceirização", compreendida sob a forma de contratos de gestão ou termos de parcerias para a execução de atividades-meio, depois atividades-fim, entre a Administração Pública e a pessoa jurídica de direito privado, a partir de um contexto histórico normativo de resultados, tanto do ponto de vista da extensão, quanto da ampliação de seus conteúdos em relação à precarização das condições laborais do trabalhador.

Pretende-se discorrer sobre algumas espécies de argumentações discursivas, usadas para convencer dos efeitos da decisão do RE $n^{\circ} 760.931 / D F$, que mais bem dissimulam as relações econômicas, sociais e ambientais desfavoráveis ao hipossuficiente, empregado terceirizado.

Além disso, seguindo a perspectiva crítica à globalização e ao capitalismo, propõe-se a realizar uma abordagem sobre o Estado Neoliberal e a postura dos poderes Judiciário e Legislativo. No mesmo sentido, entende-se que essas análises não podem prescindir de considerações acerca do direito e de suas funções, enquanto mantenedor das relações de poder e agente social catalizador de tais práticas "precarizantes".

Nessa pesquisa será utilizado o método de abordagem hipotético dedutivo, em que se busca a eliminação dos erros da hipótese: "a administração pública tornou-se mais "moderna e eficiente" com a adoção das medidas terceirizantes", ao contrário, o texto procurará testar a falsidade dessa proposição, ou seja, a partir da demonstração das consequências jurídico-normativas e sociais.

PALAVRAS-CHAVE

Neoliberalismo;

terceirização;

Administração pública; RE

760931/DF; Lei no $13.429 / 2017$

PALABRAS CLAVE

Neoliberalismo;

tercerización;

Administración pública; RE

760931/DF; Ley

$\mathrm{n}^{0} 13.429 / 2017$

KEYWORDS

Neoliberalism;

outsourcing;

public sector;

Appeal to

Supreme Court

No. 760.931/

Brazilian Federal

District; Act No.

13.429/2017

Recibido:

09.10.2017

Aceptado:

08.06.2018

\section{2. "Terceirização" na Administração Pública: a liberalização promovida pelo Poder Judiciário}

A ausência de uma legislação clara sobre "terceirização" na administração pública e os efeitos perniciosos que ela passou a acarretar às relações de trabalho, fizeram com que o Tribunal Superior do Trabalho (TST) "regulamentasse" este mecanismo de contratação, através da Súmula n 331/1993.

Dessa forma, assentando o entendimento de Tribunais Regionais do Trabalho e do próprio TST, o Órgão Superior concebeu que haveria responsabilidade subsidiária ao "tomador de serviços", dos órgãos da administração pública direta e indireta, como as autarquias, fundações públicas, empresas públicas e sociedades de economia mista, quando, ao prestar atividade-meio para a administração pública, o "terceiro contratado" descumprisse obrigações trabalhistas relativas ao trabalhador terceirizado'. 
Em virtude desse posicionamento e em função da rotina de responsabilização subsidiária do Poder Público, foi proposta a Ação Declaratória de Constitucionalidade - ADC $n^{\circ}$ 16/DF, (2007) relativa à constitucionalidade, ou não, da aplicação do art. $71, \S 1^{\circ}$ da Lei Federal $n^{\circ}$ 8666/93, referente à proibição expressa de transferência, consequente e automática, dos encargos trabalhistas, fiscais e comerciais, resultantes da execução do contrato à administração.

Em novembro de 2010, o STF julgou pela constitucionalidade do respectivo dispositivo, salvaguardando, uma vez constatada a culpa da Administração no caso concreto, a possibilidade de responsabilização, no tocante aos deveres de fiscalização do respectivo contrato de prestação de serviços (Brasil, 2011).

Apesar do TST ter adequado a redação da sua Súmula $n^{\circ} 331$ ao entendimento do STF${ }^{2}$, em 2011, continuou a aplicar a responsabilização dos entes públicos quase que indistintamente, mas agora não apenas sob o argumento da responsabilidade objetiva do Estado (art. 37 , $\S 6^{\circ}$, da Constituição), mas em virtude da responsabilidade por culpa presumida, diante de falta de acompanhamento e fiscalização do contrato.

Para coibir a ação do TST, a União ingressou com o Recurso Extraordinário (RE) no 760.931/ DF no STF por entender que a aplicação do art. $37, \S 6^{\circ}$, da Constituição Federal feriria o estabelecido no julgamento da ADC $n^{\circ} 16 / D F$, além de violar a Constituição, em especial os arts. $5^{\circ}$, II, sobre a condição de que "ninguém será obrigado a fazer ou deixar de fazer alguma coisa senão em virtude de lei". É possível ainda encontrar entre os argumentos, a alusão ao art. 37, caput, com destaque ao "princípio da legalidade aplicado à Administração Pública", na hipótese, contrário ao estabelecido no art. 71 , $\S 1^{\circ}$, da Lei $n^{\circ} 8.666 / 1993$, além disso, alega-se que a culpa deveria ser provada pela parte interessada (Brasil, 2017b).

Em março de 2017, a Suprema Corte deu provimento ao Recurso Extraordinário favorável à União. Tal decisão, além de ratificar o posicionamento do STF a cerca da ADC $\mathrm{n}^{\circ}$ 16/DF, vedou a transferência automática de responsabilidade solidária ou subsidiária à administração pública contratante e transferiu para 0 trabalhador terceirizado 0 ônus da demonstração da falha inequívoca da contratação e fiscalização do contrato ${ }^{3}$.

A despeito da solução dada, havia no voto da Ministra relatora Rosa Weber outros elementos a serem considerados. Segundo a Ministra, seria possível reafirmar a tese da $A D C n^{\circ}$ $16 / D F$, no sentido de que fosse vedada a transferência automática da responsabilidade para a administração pública, cumulando o reconhecimento da hipótese da chamada "culpa presumida" e do "princípio da aptidão da prova", repassando ao ente público o ônus de comprovar que atuou de acordo com as prescrições legais. Nessa hipótese, a solução também compatibilizaria a "condição de hipossuficiência" do empregado terceirizado a luz dos princípios da cooperação e boa-fé, típicos instrumentos do processo do trabalho (Brasil, 2017b).

Ora, a "ausência de responsabilidade" é um argumento que visa obscurecer outras questões, que, a nosso ver, são merecedoras de atenção. Ainda que a Constituição não seja explícita sobre a garantia dos direitos dos trabalhadores terceirizados, não se pode esquecer que consagrou a dignidade da pessoa humana e os valores sociais do trabalho como princípios fundamentais (art. $1^{\circ}, \mathrm{III}$ e IV, CF), além do compromisso nacional contra toda $\mathrm{e}$ qualquer forma de discriminação (art. $3^{\circ}$, III e IV, CF). De modo específico, ainda se vislumbra a extensa gama de direitos sociais previstos para os trabalhadores em geral (art. 7\%/11, CF), incluindo servidores públicos (art. 37/41, CF).

Ademais, também não se pode afastar a aplicação do já mencionado, art. $37, \S 6^{\circ}$ da Constituição sobre a "responsabilidade objetiva" da Administração Pública, bem como a incidência da "teoria do risco administrativo", a qual deve ser evocada em todas as situações, inclusive no caso de danos causados aos trabalhadores terceirizados ${ }^{4}$. 
Por outro lado, entre os fundamentos do voto vencedor, sublinha-se a analogia realizada pelo Ministro Luiz Fux entre o disposto no art. $71, \S^{\circ}$ da Lei $n^{\circ}$ 8.666/1993, sobre casos de inadimplência de contratado e a não transferência à Administração Pública da responsabilidade pelo pagamento de encargos trabalhistas, fiscais e comerciais, e, a situação de "silêncio eloquente" dessa norma. Nas palavras do Ministro, "se [o legislador] quisesse, teria feito o mesmo em relação aos encargos trabalhistas", e se "não o fez, é porque entende que a Administração Pública já afere, no momento da licitação, a aptidão orçamentária e financeira da empresa contratada" (Brasil, 2017a).

Assim é que, nas conclusões dos Ministros, verificam-se a eliminação de outras formas de interpretação do ordenamento jurídico, como se a única solução fosse aquela fornecida exclusivamente pela interpretação gramatical, o que nem sempre é suficiente para responder às demandas sociais (Krell, 2014, p. 305).

Ao mesmo tempo, observa-se que a Corte Suprema não levou em consideração a própria Lei $n^{\circ} 8.666 / 1993$, que em seu art. $3^{\circ}$ prevê o respeito ao denominado "desenvolvimento nacional sustentável"5, como fundamento das contratações públicas. Também desconsiderou a aplicação do art. 67 da mesma lei, que aponta o "poder/dever" do ente público em fiscalizar os contratos administrativos de forma permanente, inclusive no tocante à violação dos direitos dos trabalhadores terceirizados ${ }^{6}$ (Brasil, 2017b).

Nesse âmbito, foi o voto do ministro Alexandre de Moraes:

Elastecer a responsabilidade do poder público em contratos de terceirização parece ser um convite para que se faça o mesmo em outras dinâmicas de colaboração com a iniciativa privada, como as concessões de serviços públicos. (...) A consolidação da responsabilidade do estado pelos débitos trabalhistas de terceiro apresentaria risco de desestímulo de colaboração da iniciativa privada com a administração pública, estratégia fundamental para a modernização do Estado (Brasil, 2017a; grifo dos autores).

Ora, essa interpretação pressupõe a crença em um "modelo gerencial" de administração pública $^{7}$, que se cristalizou com a adoção do "princípio da eficiência", aprovado pela Emenda Constitucional $n^{\circ}$ 19/98. Segundo Chiavenato (1994, p. 70), esse modelo teria sido concebido com o enfoque no aperfeiçoamento e no uso de métodos de execução das atividades e funções da administração pública a fim de que "os recursos pudessem ser aplicados da forma mais racional possível (...)". Nesse contexto, não tardaria a ser associado à ideia de que somente a "privatização, compreendida em seu sentido amplo", seria capaz de proporcionar a eficiência aos serviços públicos.

No entanto, o que se verifica é que as "terceirizações" das atividades públicas tendem a contribuir pouco para a eficiência da prestação do serviço público, ao mesmo tempo em que agravam o desequilíbrio das relações trabalhistas, em desfavor do trabalhador. Tratase do aprofundamento da "precarização" das condições de trabalho, na medida em que o "terceirizado", trabalhador na atividade pública, deixa de ter a garantia da responsabilidade subsidiária do Poder Público, restringindo-se às condições de trabalho praticadas pela iniciativa privada em flagrante desamparo constitucional.

Além disso, é possível constatar que tal decisão tem o condão de incentivar a ampliação dos contratos de "terceirização" na administração pública, tendo em vista que a conclusão pela irresponsabilidade administrativa, não mais funcionará como uma barreira aos descumprimentos dos direitos do trabalhador.

\section{A ampliação da terceirização pela Lei no $13.429 / 2017$ e sua aplicabilidade do setor público}

Um dia após a decisão do STF, em sede de RE $n^{\circ}$ 760.931/DF, promulgou-se a Lei $n^{\circ}$ 13.429/2017, que alterou profundamente a Lei 
$\mathrm{n}^{\circ}$ 6.019/1974, sobre o trabalho temporário nas empresas urbanas. Essa lei trata da clássica situação de "terceirização", qual seja: o "trabalho temporário", originalmente descrito como sendo aquele prestado por pessoa física a uma empresa para atender necessidade transitória de substituição de pessoal regular e permanente ou acréscimo extraordinário de serviços. À época, essa espécie de intermediação de mão de obra somente poderia ocorrer por três meses, salvo autorização concedida pelo órgão do Ministério do Trabalho ${ }^{8}$.

A Lei $n^{\circ}$ 13.429/17 modificou o conteúdo do "trabalho temporário" (art. $2^{\circ}$ ) também conhecido como: "locação de mão de obra por empresa interposta", passando a ser identificado como o trabalho prestado por "uma pessoa física contratada por uma empresa de trabalho temporário que a coloca à disposição de uma empresa tomadora de serviços" para atender casos de "necessidade de substituição transitória de pessoal permanente ou à demanda complementar de serviços", com duração de cento e oitenta dias, e possibilidade de prorrogação para mais noventa dias (art. 10, $\left.\S 1^{\circ}\right)$.

A lei ainda estendeu o contrato de trabalho temporário para atividades-meio e atividades fim a serem executadas na empresa tomadora de serviços ${ }^{9}$, acompanhando os entendimentos jurisprudencial e doutrinário majoritários, que já haviam confirmado essa posição para situações temporárias e excepcionais.

Ademais, a norma também regulamentou outra modalidade de terceirização, qual seja: o "contrato de prestação de serviços", que, até então, costumava orientar-se pela Súmula $n^{\circ}$ 331.

Nesse caso, a lei não foi clara quanto à possibilidade de terceirização, ou não, de atividade-fim, ao contrário, a norma optou por um conceito jurídico indeterminado a ser preenchido pelas decisões dos tribunais.

Nesse sentido, o STF parece caminhar na mesma direção do "contrato temporário", estendendo seus efeitos para terceirização na atividade-fim da empresa na modalidade contrato de "prestação de serviços":

\section{A dicotomia entre "atividade-fim" e "atividade-meio" é imprecisa, artificial e ignora a dinâmica da economia moderna, caracterizada pela especialização e divisão de tarefas com vistas à maior eficiência possível, de modo que frequentemente o produto ou serviço final comercializado por uma entidade comercial é fabricado ou prestado por agente distinto, sendo também comum a mutação constante do objeto social das empresas para atender a necessidades da sociedade, como revelam as mais valiosas empresas do mundo (Brasil, 2017b; grifo dos autores).}

No entanto, não tardou para a publicação da Lei $n^{\circ} 13.467 / 2017$, denominada de "reforma trabalhista", que acabou por promover outra alteração na Lei $n^{\circ} 6.019 / 1974$, passando a prever de forma expressa a possibilidade de terceirização na atividade-fim das empresas, mesmo na modalidade prestação de serviços, através da fórmula "inclusive sua atividade principal".

De qualquer modo, qualquer uma dessas modalidades de "contratos" parecem não ser integralmente aplicáveis quando se refere à administração pública. O "contrato temporário", por exemplo, tem efeito limitado, seja em função da exigência expressa de realização de concurso público para investidura de cargos, empregos e funções (art. 37, II CF), seja pelo tratamento específico quanto à contratação de "trabalhador temporário", que somente pode ocorrer em situação de excepcionalidade e no devido interesse público (art. 37, IX CF) ${ }^{10}$ (Pietro, 2017, p. 271).

Já o "contrato de prestação de serviços" na administração pública se encontra regulado pelo Decreto-lei $n^{\circ} 200 / 1967$, que permite a descentralização para a realização de atividades executivas ou operacionais ("atividades-meio"), como transporte, conservação, custódia, limpeza (art. $3^{\circ}$, § único da Lei $n^{\circ} 5.645 / 1970{ }^{11}$ ). 
$\mathrm{Na}$ mesma esteira, a Lei $\mathrm{n}^{\circ} 8.666 / 1993$ autoriza a "contratação de serviços", visando a obtenção de "determinada utilidade de interesse para a Administração"12, prevendo em suas hipóteses, a "contratos de prestação de serviços técnicos especializados" (art. 13) para casos determinados ${ }^{13}$.

Para alguns autores, a "terceirização" prevista na nova Lei $n^{\circ}$ 13.429/2017 teria também alcançado a administração pública, desde que observadas as regras de direito público. Em todo o caso, a "terceirização" somente seria admitida nas situações de "serviços previa e especificadamente determinados", ou seja, na condição de "atividade-meio", desde que ausentes "a pessoalidade e a subordinação" direta com o ente público (Garcia, 2017, p. 25).

Segundo Frediani (2017, pp. 108-109), a legislação brasileira se aproximou das legislações de países centrais quando passou a regulamentar a "terceirização". Para esse autor, Espanha, já a algum tempo, admite a contratação "por meio de empresa de trabalho temporário" com o fim de suprir a necessidade de mão de obra temporária da empresa tomadora". A legislação espanhola também prevê a possibilidade de subcontratação de empresas permitindo a descentralização dos serviços nos termos do art. 42 do Estatuto dos Trabalhadores.

Diferentemente do Brasil, esta legislação também prevê hipótese de responsabilidade solidária entre ente público e tomador dos serviços, garantia de igualdade e não discriminação, regras que visam uma seleção idônea da empresa a ser contratada (Frediani, 2017, p. 108-109). Além dessas garantias legislativas, há outra diferença substancial: a efetividade da observância das normas inerentes às relações laborais, que no Brasil ainda é um fenômeno longe de ser observado ${ }^{14}$.

\section{Ideologia dominante dos poderes: neoliberalismo}

Desde a década de 1960, o Direito do Trabalho vê a sua efetividade sendo mitigada. Um fator recorrentemente constitutivo dos retrocessos na proteção normativa é o "artificialismo nominativo", manifestado na elaboração de neologismos e formas jurídicas "inovadoras" que visam amenizar o recrudescimento da exploração do trabalhador e o desmonte de legislações (Maior, 2008, p. 162). São exemplos desta categoria os termos "terceirização", "colaborador" e as modalidades de trabalho autônomo, part in time, "temporário", entre outros.

A "nova realidade do mercado mundial" que condicionaria essas modificações é caracterizada pelo capitalismo neoliberal que se vale da reestruturação produtiva em escala global para manter e/ou ampliar os lucros das grandes corporações (Antunes, 2015, p. 34). De acordo com Mészáros,

(...) só pode haver um caminho para tentar alargar as margens contraídas da acumulação de capital: às expensas do trabalho. Isso é uma estratégia promovida ativamente pelo Estado - na verdade, devido a essa necessidade, o papel intervencionista do Estado nunca foi tão grande como neste nosso tempo, apesar de toda a mitologia neoliberal em contrário (...) (Mészáros, 2015, pp. 38$39)$.

Esse complexo e inacabado processo de reorganização do modo de produção capitalista impõe a hegemonização das "situações de mercado", até que estas se tornem regras únicas de sociabilidade. Priorizam-se, portanto, privatizações, desregulamentações de direitos sociais, concorrências, mercadorização e o fomento ao sistema da dívida pública ${ }^{15}$ (Dardot; Laval, 2016, p. 217).

O neoliberalismo aprofunda a agressividade da extração da mais valia relativa e absoluta do sistema capitalista na conjuntura da globalização (Mészáros, 2015, p. 38). Tendo início nos países centrais, estendeu-se aos países subordinados, onde causou maiores 
impactos, ao considerar-se a realidade de exploração e da divisão internacional de trabalho, bem como a inexistência da realização de requisitos mínimos do Estado Social. Além disso, os países subdesenvolvidos possuem legislações mais permissivas e grande exército industrial de reserva, barateando o preço da mão-de-obra (Dardot; Laval; 2016, p. 222).

$\mathrm{Na}$ América Latina, a sistematização da cartilha neoliberal se deu pelo Consenso de Washington ${ }^{16}$ (capitaneado pelos EUA e organizações financeiras internacionais, FMI e Banco Mundial ${ }^{17}$ ) que abrangeu questões relativas a

1. disciplina fiscal; 2. priorização dos gastos públicos; 3. reforma tributária; 4. liberalização financeira; 5. regime cambial; 6. liberalização comercial; 7. investimento direto estrangeiro; 8. privatização; 9. desregulamentação; e 10. propriedade intelectual (Batista, 1994, p. 18).

Considerando-se as singularidades da implementação do neoliberalismo nestes países, o objetivo neoliberal é o de apresentar um Estado mínimo para os cidadãos e máximo para o grande mercado, invertendo-se a lógica de cidadania e transformando o Estado numa grande empresa, na qual os cidadãos passam a ser consumidores ou acionistas de serviços, antes considerados direitos (Santos, 2009, p. 49). Ainda neste sentido, vige o grande princípio da "nacionalização dos riscos e da privatização dos lucros” (Dardot; Laval, 2016, p. 204).

O papel desempenhado pelos governos foi essencial para o deslinde da política neoliberal. O Estado assumiu o papel de "construtor, vetor e parceiro do capitalismo financeiro", estendendo forçada e forçosamente a sua função de guardião das regras jurídicas da nova ordem, expressas nas contrarreformas (Dardot; Laval, 2016, p. 205). Para tanto, uma série de "discursos, práticas e dispositivos de poder" foram engendrados para sua concretização (Dardot; Laval, 2016, p. 191).
A lógica da empresa toyotista (característica do capitalismo neoliberal), flexível, moderna, enxuta, multivariável e vinculada aos fluxos da demanda, é transposta para o Estado e para o serviço público (Antunes, 2015, pp. 248249). Ao mesmo tempo, a noção de trabalho regulamentado e contratado é corroída, havendo "a sua substituição pelas terceirizações, por diferentes modos de flexibilização, pelas formas de trabalho part in time, pelas diversas formas de 'empreendedorismo', 'cooperativismo', 'trabalho voluntário', 'terceiro setor' etc." (Antunes, 2015, p. 250).

Por último, inverte-se a lógica protetiva do trabalho, criando-se autoritariamente uma legislação "antitrabalho" que tem por função extinguir "mercados rígidos de trabalho" (Mészáros, 2006, p. 34). Persegue-se a eliminação das formas de responsabilização do empregador em nome da "racionalização do capital" (Dardot; Laval, 2016, pp. 231232), garantindo-lhe a criação de institutos jurídicos que atribuam maior autonomia contratual ao trabalhador - ainda que fictícia, pois é permanente a situação de exploração de trabalho (Maior, 2008, p. 162).

István Mészáros (2015, p. 32), aduz que há uma globalização do desemprego e da precarização, demandados pelos "imperativos antagônicos do capital, da busca do lucro e da acumulação", que causam impactos significativos nas economias de todo o mundo.

Mesmo antes do neoliberalismo, a classe trabalhadora brasileira já passava por um "processo de superexploração do trabalho, que articulava baixos salários às jornadas de trabalho intensas e prolongadas" (Antunes, 2015 , p. 232). Estes fatores, combinados ao processo de reestruturação produtiva e (re) inserção no sistema produtivo global do capital (a partir da década de 1990), implicaram num fortalecimento dessa situação de labor (Antunes, 2015, p. 233).

A expansão do desemprego estrutural aprofundou o sistema concorrencial para os trabalhadores, minando a organização coletiva/ sindical. Já as práticas de "informalidade" laboral enraizaram-se no cotidiano da sociedade 
brasileira: "terceirizados, precarizados, subcontratados, flexibilizados, trabalhadores em tempo parcial, subproletariados" (Antunes, 2015, p. 252).

Ao mesmo tempo em que as vagas de trabalho regulamentadas vão diminuindo, a classeque-vive do trabalho é ampliada, dando lugar a formas cada vez mais precarizadas e desregulamentadas que englobam uma população heterogênea, com trabalhadores qualificados ou não, das mais variadas faixas etárias, destacando a inserção precoce de crianças e a superexploração potencializada de mulheres, lgbts, imigrantes e negros (Antunes, 2009, pp. 237-238).

A precarização estrutural do trabalho promovida pelos capitais globais reivindica dos governos nacionais o desmantelamento dos direitos e legislações sociais, o que implica, portanto, numa "maior extração do sobretrabalho". As empresas modernas, racionalizadas, intensificam os níveis de exploração do trabalho, "agora no sentido de perdas e liames e da erosão da regulamentação e da contratação" (Antunes, 2015, p. 250). Com a maior flexibilização, verifica-se a intensificação dos "mecanismos de controle e de subordinação" sobre a classeque-vive-do-trabalho (Antunes, 2015, p. 251), espraiando-se sobre todos os ramos nos quais existe a relação de trabalho.

Menos trabalhadores, por conta do desemprego estrutural, laboram em ritmo e intensidade semelhantes ao capitalismo no início a Revolução Industrial, reduzindo-se o trabalho estável pela necessidade de explorar ao máximo a força de trabalho (Antunes, 2015, p. 252). Além da informalidade, o medo e a insegurança da perda do emprego permeiam as relações de trabalho, o que faz com que a classe trabalhadora se submeta a condições cada vez mais débeis de trabalho e a reduzidos salários.

\section{Considerações finais}

Sob o ponto de vista exclusivamente econômico, a "terceirização" aumenta os lucros e as vantagens do empregador contratante, pois o aumento da jornada de trabalho se combina com a redução das remunerações e direitos. Em nome da amplitude da margem de ganhos do contratante, fomenta-se a produção de legislações e decisões antitrabalhistas que asseguram a formação de "trabalhadores (contratados) de segunda classe", os quais, sob o ponto de vista social e ambiental, arcam com todos os prejuízos e danos a sua qualidade de vida e de sua família.

Por esse prisma, o Estado atua por meio de suas estruturas, sob a forma do processo jurídico e da decisão judicial, e de sua estruturação, que se encontra impressa nos conteúdos das leis e das decisões judiciais dos magistrados, para produzir e reproduzir as classificações mentais e percepções distintas da realidade, manifestada pela "racionalização do capital". No caso concreto do Estado brasileiro, observase pelo menos desde a década de 90, uma clara inflexão à satisfação exclusiva das diretrizes do mercado financeiro, em que o projeto de administração pública se caracteriza pela solução econômica da "eficiência" gerencial.

Se bem que o resultado do $R E n^{\circ} 760.931 / D F$ tenha um final conhecido: "a irresponsabilidade automática da Administração Pública no tocante ao adimplemento das verbas trabalhistas dos trabalhadores terceirizados", esse trabalho objetivou realizar algumas ponderações sobre uso da linguagem e da argumentação, dita jurídica, sobre as decisões judiciais e do conteúdo normativo da Lei $\mathrm{n}^{\circ}$ 13.429/2017. 


\section{NOTAS}

${ }^{1}$ Esse entendimento toma por base 0 art. 37, $\S 6^{\circ}$ da Constituição brasileira, assim disposto: "Art. 37. A administração pública direta e indireta de qualquer dos Poderes da União, dos Estados, do Distrito Federal e dos Municípios obedecerá aos princípios de legalidade, impessoalidade, moralidade, publicidade e eficiência e, também, ao seguinte:[...] $\S 6^{\circ}$ As pessoas jurídicas de direito público e as de direito privado prestadoras de serviços públicos responderão pelos danos que seus agentes, nessa qualidade, causarem a terceiros, assegurado o direito de regresso contra o responsável nos casos de dolo ou culpa".

2 SÚMULA 331, TST: “(...) II - A contratação irregular de trabalhador, mediante empresa interposta, não gera vínculo de emprego com os órgãos da Administração Pública direta, indireta ou fundacional (art. 37, II, da CF/1988). (...) V - Os entes integrantes da Administração Pública direta e indireta respondem subsidiariamente, nas mesmas condições do item IV, caso evidenciada a sua conduta culposa no cumprimento das obrigações da Lel $n^{\circ}$ 8.666, de 21.06.1993, especialmente na fiscalização do cumprimento das obrigações contratuais e legais da prestadora de serviço como empregadora. A aludida responsabilidade não decorre de mero inadimplemento das obrigações trabalhistas assumidas pela empresa regularmente contratada (...)" (grifo dos autores).

3 Trata-se de recurso extraordinário proposto pela União em face de Priscila Medeiros Nunes e Evolution Administradora de Serviços Terceirizada Ltda. Tendo como relatora a Ministra Rosa Weber, seu voto foi acompanhado pelos ministros Edson Fachin, Luís Roberto Barroso, Ricardo Lewandowski e Celso de Mello. No entanto, o voto vencedor foi o do ministro Luiz Fux, seguido pelos ministros Marco Aurélio, Gilmar Mendes, Dias Toffoli, Cármen Lúcia e Alexandre de Morais. As informações trazidas abaixo foram extraídas com base nos informativos do STF de $n^{\circ} 852,853,854,859$ e 862 , bem como no inteiro teor do acórdão. Essa decisão produzirá efeitos para em média cinquenta mil processos que se encontravam suspensos.

${ }^{4}$ Segundo Pietro (2010, p. 646), essa doutrina tem como base o princípio da igualdade e o art. $13 \mathrm{da}$ Declaração dos Direitos do Homem, que prevê que "para a manutenção da força pública e para as despesas de administração é indispensável uma contribuição comum que deve ser dividida entre os cidadãos de acordo com as suas possibilidades". Assim, como se repartem os benefícios oriundos da atuação do Estado, também devem ser repartidos os prejuízos de algum membro específico da sociedade, se rompe o equilíbrio entre os sujeitos pela atuação do poder público, "o Estado deve indenizar o prejudicado, utilizando recursos do erário".

${ }^{5}$ O princípio do desenvolvimento nacional sustentável possui duas dimensões: uma ecológica, que visa a adoção de práticas ambientais adequadas; e outra econômico-social, que "consiste num processo de incremento de riqueza acompanhado da elevação da qualidade de vida" (Justen Filho, 2011).
${ }^{6}$ Voto da Ministra Rosa Weber (Brasil, 2017, Informativo $n^{\circ}$ 852). Na mesma linha, o ministro Luís Roberto Barroso afirma que a fiscalização do ente público é uma obrigação de meio e não de resultado, pode inclusive ser realizada por amostragem com apoio técnico do órgão de controle externo, que terá presunção relativa de razoabilidade, devendo notificar a empresa terceirizada em caso de descumprimento de suas obrigações, e na manutenção da irregularidade, deve promover ação de depósito, com a liquidação e o pagamento das parcelas devidas aos trabalhadores, com o devido abatimento dos valores da empresa contratada (Brasil, 2017b).

7 O novo modelo gerencial foi proposto, a partir da década de 90 , como resposta ao mercado financeiro, que exigia além de um ajuste fiscal, a desregulamentação de direitos e a privatização de setores estratégicos do Estado (Castro, 2006).

8 A Portaria do Ministério do Trabalho e Emprego $n^{\circ} 789 / 2014$ disciplina as hipóteses de prorrogação permitindo a ampliação para um prazo de até três meses.

${ }^{9}$ Art. 90: § $30 \mathrm{O}$ contrato de trabalho temporário pode versar sobre o desenvolvimento de atividades-meio e atividades-fim a serem executadas na empresa tomadora de serviços" (NR).

10 No âmbito da União, este tipo de contratação foi regulado pela Lei $n^{\circ} 8.745 / 1993$, onde consta a necessidade de processo seletivo simplificado, prevê os prazos e os direitos correspondentes.

${ }^{11} \mathrm{O}$ parágrafo único do artigo $3^{\circ}$ da lei mencionada foi revogado pela Lei $n^{\circ} 9.527 / 1997$, no entanto, o conjunto normativo e o entendimento jurisprudencial normativo não pode levar a conclusão que a sua revogação levaria a possibilidade de terceirização em qualquer atividade da Administração Pública.

${ }^{12}$ Art. 6: II - Serviço - toda atividade destinada a obter determinada utilidade de interesse para a Administração, tais como: demolição, conserto, instalação, montagem, operação, conservação, reparação, adaptação, manutenção, transporte, locação de bens, publicidade, seguro ou trabalhos técnico-profissionais.

${ }^{13}$ Segundo Pietro (2017, p. 272) não é incomum verificarse a burla da legislação, justificada pelo objetivo de fornecimento de mão de obra sem concurso público.

14 Somente em 2016 foram registrados 4.262.444 processos novos na Justiça Trabalhista (CNJ, 2017, p. $69)$.

${ }^{15} \mathrm{O}$ sistema da dívida pública "corresponde à utilização do endividamento público às avessas, ou seja, em vez de servir para aportar recursos ao Estado, o processo de endividamento tem funcionado como um instrumento que promove uma contínua e crescente subtração de recursos públicos, que são direcionados principalmente ao setor financeiro privado" (Fattoreli, 2017). 
${ }^{16}$ Importante reforçar que apesar de não haver caráter legal cogente, o Consenso condicionava a concessão de empréstimos e auxílios aos países à adesão das diretrizes previstas (Dardot; Laval, 2016, p. 197).

${ }^{17}$ As duas organizações ganham importância central no desenvolvimento do capitalismo a partir da década de 1980, com a hegemonização do capitalismo financeiro e consequentes intervenções que passaram a realizar nos países para a garantia do "quadro político do Estado concorrencial” (Dardot; Laval, 2016, p. 198).

\section{REFERÊNCIAS BIBLIOGRÁFICAS}

Antunes, R. (2009). Século XXI: nova era da precarização estrutural do trabalho? In R. Antnes, R. Braga (Orgs.). Infoproletários. Degradação real do trabalho virtual. São Paulo: Boitempo.

Antunes, R. (2015). Os sentidos do trabalho. Ensaio sobre a afirmação e a negação do trabalho. São Paulo: Boitempo.

Bastos, G. A. C. (2010). Terceirização - aspectos polêmicos. In M. G. Delgado et al. (Coords.). A efetividade do direito e processo do trabalho. Rio de Janeiro: Elsevier.

Batista, P. (1994). O Consenso de Washington. A visão neoliberal dos problemas latino-americanos. In B. Lima Sobrinho, et al. (Org.). Em defesa do interesse nacional: desinformação e alienação do patrimônio público. São Paulo: Paz e Terra.

Borba, J. N. (2017). Externalização produtiva: subcontratação e terceirização. Como não precarizar? Necessária aplicação do princípio da igualdade. In G. F. B. Garcia \& R. Z. de Alvarenga (Coords.). Terceirização de serviços e direitos sociais trabalhistas. São Paulo: LTr, 2017.

Brasil. (1967). Decreto-lei $n^{\circ} 200$, de 25 de fevereiro de 1967. Dispõe sobre a organização da Administração Federal, estabelece diretrizes para a Reforma Administrativa e dá outras providências. Diário Oficial [da] República Federativa do Brasil. Brasília, DF, 27 fev. 1967. Recuperado de [http://www.planalto.gov.br/ ccivil_03/decreto-lei/Del0200.htm]. Consultado [08-052017].

Brasil. (1974). Lei $n^{\circ}$ 6.019, de 3 de janeiro de 1974. Dispõe sobre o Trabalho Temporário nas Empresas Urbanas, e dá outras Providências. Diário Oficial [da] República Federativa do Brasil. Brasília, DF, 4 jan. 1974. Recuperado de [http://www.planalto.gov.br/ccivil_03/ leis/L6019.htm]. Consultado [12-05-2017].

Brasil. (1988). Constituição Federal. Constituição da República Federativa do Brasil. Brasília, 5 de outubro de 1988. Recuperado de [http://www.planalto.gov.br/ ccivil 03/constituicao/ConstituicaoCompilado.htm]. Consultado [08-05-2017].

Brasil. (1993). Lei $n^{\circ}$ 8.666, de 21 de junho de 1993. Regulamenta o art. 37, inciso XXI, da Constituição Federal, institui normas para licitações e contratos da Administração Pública e dá outras providências. Diário Oficial [da] República Federativa do Brasil. Brasília, DF, 22 jun. 1993. Recuperado de [http://www.planalto.gov. br/ccivil_03/leis/L8666cons.htm]. Consultado [12-052017].

Brasil. (1997). Decreto $n^{\circ} 2.271$, de 7 de julho de 1997. Dispõe sobre a contratação de serviços pela Administração Pública Federal direta, autárquica e fundacional e dá outras providências. Diário Oficial [da] 
República Federativa do Brasil. Rio de Janeiro, RJ, 8 jul. 1997. Recuperado de [http://www.planalto.gov.br/ ccivil_03/decreto/d2271.htm]. Consultado [14-05-2017].

Brasil. (2007). Projeto de Lei $n^{\circ} 1.621$, de 12 de julho de 2007. Dispõe sobre as relações de trabalho em atos de terceirização e na prestação de serviços a terceiros no setor privado e nas sociedades de economia mista. Recuperado de [http://www.camara.gov.br/ proposicoesWeb/prop_mostrarintegra;jsessionid $=382 \mathrm{C}$ A59CFBB7DB5832858CEB61B70AFC.proposicoesWe bExterno1 codteor $=483435$ \&filename $=P L+1621 / 2007]$. Consultado [15-05-2017].

Brasil. (2011). Supremo Tribunal Federal. Ação Declaratória de Constitucionalidade $n^{\circ}$ 16/DF Governador do Direito Federal. Relator: Ministro Cezar Peluso. DJe de 9 set. 2011.

Brasil. (2017a). Supremo Tribunal Federal. Recurso Extraordinário $n^{\circ}$ 760.931/DF. União e Priscila Medeiros Nunes, Evolution Administradora de Serviços Terceirizada Ltda. Relatora: Ministra Rosa Weber. DJe de 11 set. $2017 \mathrm{c}$.

Brasil. (2017b). Supremo Tribunal Federal. Recurso Extraordinário $n^{\circ}$ 760.931/DF. União e Priscila Medeiros Nunes, Evolution Administradora de Serviços Terceirizada Ltda. Relatora: Ministra Rosa Weber. Informativos $\mathrm{n}^{\circ}$ 852, 853, 854, 859 e 862. Recuperado de [http://www. stf.jus.br/portal/informativo/pesquisarlnformativo.asp]. Consultado [16-05-2017].

Caldeira, J. P. (2017). Sistema da dívida pública impede os direitos sociais, diz Maria Lúcia Fattorelli. Jorna GGN. Recuperado de [https://jornalggn.com.br/noticia/ sistema-da-divida-publica-impede-os-direitos-sociaisdiz-maria-lucia-fatorelli]. Consultado [01-10-2017].

Castro, R. (2006). Eficácia, Eficiência e Efetividade na Administração Pública. In Anais ENANPAD, Salvador.

Chiavenato, I. (1994). Recursos humanos na Empresa: pessoas, organizações e sistemas ( $3^{\mathrm{a}}$ ed). São Paulo: Atlas.

Conselho Nacional de Justiça (CNJ). (2016). Justiça em números 2017: ano-base 2016. Brasília: CNJ.

Dardot, P. \& Laval, C. A nova razão do mundo. Ensaio sobre a sociedade neoliberal. São Paulo: Boitempo.

Delgado, M. G. Curso de direito do trabalho $\left(14^{\mathrm{a}} \mathrm{ed}\right)$. São Paulo: LTr.

DIEESE. (2017). Terceirização e precarização das condições de trabalho: condições de trabalho $e$ remuneração em atividades tipicamente terceirizadas e contratantes. São Paulo: Departamento Intersindical de Estatísticas e Estudos Socioeconômicos.

Frediani, Y. (2017). Terceirização de serviços - um estudo sintético e comparado com os ordenamentos espanhol e italiano. In G. F. B. Garcia \& R. Z. de Alvarenga (Coords.).
Terceirização de serviços e direitos sociais trabalhistas. São Paulo: LTr, 2017.

Garcia, G. F. B. (2017). Terceirização de serviços na Administração Pública: limitações e consequências jurídicas. In G. F. B. Garcia \& R. Z. de Alvarenga (Coords.). Terceirização de serviços e direitos sociais trabalhistas. São Paulo: LTr.

Krell, A. J. (2012). Para além do fornecimento de medicamento para indivíduos - O exercício da cidadania jurídica como resposta à falta de efetivação dos direitos fundamentais sociais: em defesa de um ativismo judicial moderado no controle de políticas públicas. In E. Feitosa, et al. (Org.). O judiciário e o discurso dos direitos humanos (vol. 2). Recife: Ed. Universitária da UFPE.

Krell, A. J. (2014). Entre desdém teórico e aprovação na prática: os métodos clássicos de interpretação jurídica. São Paulo: Revista de Direito GV

Maeda, P. (2017). A Era dos zero direitos: trabalho decente, terceirização e contrato zero hora. São Paulo: LTr, 2017.

Maior, J. L. S. (2008). A supersubordinação - invertendo a lógica do jogo. Revista do Tribunal Regional do Trabalho da $3^{\text {a }}$ Região, 48(78), 157-193.

Mészáros, I. (2015). Desemprego e precarização: um grande desafio para a esquerda. In R. Antunes (Org.). Riqueza e miséria do trabalho no Brasil. São Paulo: Boitempo.

Pietro, M. S. Z. di. (2017). Parcerias na administração pública $\left(11^{\mathrm{a}}\right.$ ed). Rio de Janeiro: Forense.

Santos, M. (2009). Por uma outra globalização. Rio de Janeiro: Record. 